\title{
Antimicrobial Activity and Synergistic Antimicrobial Potential of Silver Nanoparticles against microbial contaminants isolated from pharmaceutical production areas
}

\author{
Mahmoud Aabdallah *, Abeer Bayoumy and Atef Ibrahim,
}

Genetic Engineering and biotechnology Researches Institute (GEBRI), university of Sadat City, Egypt.

Corresponding author: Email:azzazy73@gmail.com

\begin{abstract}
Silver nanoparticles play a vital role in the development of new antimicrobial substances against a number of pathogenic microorganisms. These nanoparticles due to their smaller size could be very effective as they can improve the antibacterial activity through lysis of bacterial cell wall. The biosynthesis of nanoparticles as an emerging highlight of the intersection of nanotechnology and biotechnology has received increasing attention due to a growing need to develop environmentally benign technologies in material synthesis (Kalishwaralal et al., 2008).

In the present investigation, synthesis of silver nanoparticles (AgNPs) was attempted using the isolated pharmaceutical contaminants. The synthesized AgNPs were evaluated for their antibacterial activity against common pharmaceutical contaminants. When AgNPs were mixed with hydrogen peroxide disinfectant they displayed strong synergistic antibacterial.

The overall results highlighted the potential use of commonly isolated microorganisms from pharmaceutical industrial areas in the synthesis of AgNPs and their utilization in various applications particularly as antibacterial substance in disinfection and preservation to protect against various biomedical, pharmaceutical based activities.
\end{abstract}

Key words: Environmental monitoring, settle plate, contact plate, antibacterial, silver nanoparticles.

\section{INTRODUCTION}

Nanoscience and nanotechnology are the study and application of extremely small things and can be used across all the other scientific fields, such as chemistry, biology, physics, materials science and engineering conducted at the nanoscale, which is about 1 to 100 nanometers (Natarajan et al., 2010). Investigation of novel properties of nanoparticles and their application has become a very active area of research. Nanoparticle having one or more dimensions of the order of $100 \mathrm{~nm}$ or less- have attracted considerable attraction due to their unusual and fascinating properties, with various applications, over their bulk counterparts. Currently, a large number of physical, chemical, biological, and hybrid methods are available to synthesize different types of nanoparticles. Though physical and chemical methods are more popular for nanoparticle synthesis, the use of toxic compounds limits their applications (Gopinath et al., 2013a). Practically, this effort has involved the design, production, and characterization of a multidimensional nanostructures including nanoparticles, nanocubes, nanorods, nanowires, and nanotubes, which maintain essentially interesting sizedependent electronic, optical, thermal, mechanical, magnetic, chemical, and other 
physical properties. These structures have wide ranging utility from the perspective of applications in areas as diverse as catalysis, energy storage, fiber engineering, fuel cells, biomedicine, computation, power generation, photonics, pollution remediation, and sensing (Fulekar et al., 2014).

The development of safe eco-friendly methods of biogenetic production are now of more interest due to the simplicity of the procedures and versatility. Due to their amenability to biological functionalization, the biological nanoparticles are finding important applications in the field of medicine. The antimicrobial potential of metal based nanoparticles has led to its incorporation in consume, health related and industrial products. Our area of interest lies in the biological synthesis of gold silver nanoparticles (Gopinath et al., 2013a). Progress in the field of nanotechnology has been rapid and with the development of innovative synthesis protocols and characterization techniques. But most of the synthesis methods are limited to synthesis of nanoparticles in small quantities and poor morphology (Sau, 2010). Nowadays Investment in nanotechnology is a point of interest by governmental, academic, economic and applied companies in more developed countries due to their new innovations of chemical, physical and biological characteristics according to the Organization for Economic Co-operation and Development, patent data used as a source of information in order to evaluate scientific and technology activities (Antunes et al., 2013).

Silver nanoparticles are nanoparticles of si lver of between $1 \mathrm{~nm}$ and $100 \mathrm{~nm}$ in size. Silver nanoparticles have unique optical, electrical, and thermal properties and are being incorporated into products that range from photovoltaic to biological and chemical sensors (Oldenburg and $\mathrm{Ph}$, 2014). Silver nanoparticles possess unique properties with numerous applications such as antimicrobial, anticancer, larvicidal, catalytic, and wound healing activities. Biogenic syntheses of silver nanoparticles and their pharmacological and other potential applications are gaining momentum owing to its assured rewards (Firdhouse and Lalitha, 2015).

Chemical and physical synthesis methods often result in synthesis of a mixture of nanoparticles with poor morphology, and these methods also prove to be toxic to the environment due to the use of toxic chemicals and also of elevated temperatures for synthesis process (Rai et al., 2011). In this regard, fungi, bacteria, algae, yeasts, and plants have inherent capacities to reduce metal through their specific metabolic pathway. In fact, some biomimetic (peptides) procedures are also used. Different types of metallic nanoparticles like copper, zinc, titanium, gold, and silver, among others, have been produced by biological methods. However, the interest in silver nanoparticles has been increasing due to their high antimicrobial activity against bacteria, viruses and eukaryotic microorganisms. It seems that microbes produce nanoparticles as a consequence of the detoxification pathway. But the mechanism of bioreduction of metal ions is still an open question. In general, the first step involves trapping of the metal ions on the surface of the cell, possibly via electrostatic interaction between the ions and nonionic hydroxyl groups, carboxyl groups and other negatively charged groups on the cell. Thereafter, ions are reduced by enzymes (e.g., reductase) or/and carbonyl groups leading to formation of metal nuclei, which further grow to frame crystals. Only in one example, nitrate reductase from the fungus $F$. oxysporum has been well documented to catalyze the reduction of silver nitrate to silver nanoparticles utilizing NADPH as reducing agent (Irena Maliszewska, 2011). 
Building objects molecule by molecule, resulting in near-perfect products that far surpass any existing objects in terms of performance, effectiveness and longevity. The most exciting applications of metal nanoparticles have come in breakthroughs recently, as scientists have developed ways to apply nanotechnology in medicine, robotics and the environment fields (Gupta, 2014). New innovations in molecular nanotechnology may be the solution to the world's dependency on fossil fuels. Using nanotechnology to modify materials at the atomic level has allowed scientists to produce solar cells that are five times more effective than traditional silicon-based units. Installing these new solar cells across just 0.1 percent of the earth's surface would supply enough energy to eliminate the need for oil. Even better, these small flexible solar cells could be woven into the clothes we wear to charge a cell phone or computer on the go (Liu et al., 2013).

With the concurrent rise of the fields of biomedical engineering and nanotechnology, the intersected field of nanomedical engineering has grown remarkably in the past decades (Kim et al., 2010). Preclinical research in the field of nanomedicine continues to produce a steady stream of new nanoparticles with unique capabilities and complex properties. With improvements come promising treatments for diseases, with the ultimate goal of clinical translation and better patient outcomes compared with current standards of care (Luo et al., 2015). Applications of nanotechnology can increase the efficacy of therapeutics by providing solutions to the traditional problems associated with pharmaceutical solubility, limiting systemic toxicities, bioavailability, immunocompati bility and cellular uptake. Nanotechnology based therapeutics can be produced either through top down processes such as milling, high pressurised homogenisation, etching, lithography and other methods, or through bottom up processes, such as chemical synthesis both for inorganic nanomaterials or complex polymeric designs to act as therapeutic agents or carriers of therapeutic agents (Mahapatra et al., 2013). Comprehensive studies has estimated that there are more than 250 nanomedical products that have been approved and are in the market or are in early or late stages of clinical trials, with many more in development (Etheridge et al., 2013). A market research firm, BCC research, has estimated that the nanomedical global market value increased from USD 53 billion in 2009 to USD 72.8 billion in 2011. Additionally, the firm has projected a compound annual growth rate in the global market for nanomedicines to be $12.5 \%$, between the years 2011 and 2016, with largest growth in the therapeutic area of oncology and disorders of the central nervous system (CNS). The applications currently in clinical development belong to the categories of liposomal formulations, polymer-protein and polymer-drug conjugates, micelles, antibody-drug conjugates, dendrimers, metal and metal oxide NMs (Mahapatra et al., 2013). Organic compounds used for disinfection have some disadvantages, including toxicity to the human body, therefore, the interest in inorganic disinfectants such as metal oxide nanoparticles (NPs) is increasing (Hajipour et al., 2012). Furthermore, nanorobotics, operating in the human body, could monitor levels of different compounds and store that information in internal memory. The use of nanodevices would give the additional benefits of reduced intrusiveness, increased patient comfort, and greater fidelity of results, since the target tissue can be examined in its active state in the actual host environment. They could be used to rapidly examine a given tissue location, surveying its biochemistry, biomechanics, and histometric characteristics in greater detail. This would help in better disease diagnosing (Filipe, 2015). It has also been assumed that 
nanomachines could distribute drugs within the patient's body. Such nanoconstructions could deliver medicines to particular sites, making more adequate and precise treatment possible. Such devices would have a small computer, several binding sites to determine the concentration of specific molecules, and a supply of some 'poison' that could be released selectively. Similar machines equipped with specific 'weapons' could be used to remove obstructions in the circulatory system or identify and kill cancer cells (Loeve, 2015).

More than 99\% bacteria exist in ecosystems in biofilms attached to biotic and abiotic surfaces. Biofilms are more resistant to antibiotics than planctonic cells of bacteria. The formation of biofilms on implanted surfaces (e.g., catheters, lenses, implants) leads to the development of chronic diseases. Prevention of biofilm formation on abiotic surfaces such as stents and venous catheters, urinary catheters, and implants of bone is a much better way of reducing pathogens than eliminating the bacterial biofilm. Scientists have determined the influence of silver nanoparticles on the growth of biofilm formation and the inhibition of mechanisms of action (Radzig et al., 2013). Information on proteinnanoparticles interaction and binding parameters is high significance to tailor hybrid systems of specific function with improved performance. This effort highlights utilization of fluorescence spectroscopy as a sensitive, reliable technique to monitor possible structural changes that a typical biomolecule might undergo upon interaction with nanoparticle of interest. Moreover, analysis of fluorescence data revealed a single binding site in lysozyme, having low affinity for binding to AgNPs compared to gold nanostructures. These findings encourage in-depth characterization of proteinnanoparticle interactions prior to design hybrid drug Nano carrier systems
(Ashrafpour et al., 2014). Silver nanoparticles have gained attention because of their antimicrobial activity which offers the possibility of their use for medical and hygiene purposes. Indeed, silver nanoparticles in different formulations and with different shapes and sizes exhibit variable antimicrobial activity. However, the mechanisms of antimicrobial activity of silver ions and silver nanoparticles, and their toxicity to human tissues are not fully characterized (Durán et al., 2010). Silver is more toxic element to microorganisms than many other metals in the following sequence: $\mathrm{Ag}$ $>\mathrm{Hg}>\mathrm{Cu}>\mathrm{Cd}>\mathrm{Cr}>\mathrm{Pb}>\mathrm{Co}>\mathrm{Au}>\mathrm{Zn}$ $>\mathrm{Fe}>\mathrm{Mn}>\mathrm{Mo}>\mathrm{Sn}$. And AgNPs exert more efficient than silver ions and other silver salts in mediating their antimicrobial activity. Silver exhibits low toxicity to mammalian cells. And silver has a lower propensity to induce microbial resistance than many other antimicrobial materials. As a result, AgNPs have been applied to a wide range of products; the most important current use is as antimicrobial agents to prevent infection ( $\mathrm{Li}$ et al., 2011). The ability of silver nanoparticles to release silver ions is a key to their bactericidal activity (Gopinath et al., 2013b). AgNPs have distinctive physico-chemical properties, including a high electrical and thermal conductivity, surface-enhanced Raman scattering, chemical stability, catalytic activity and non-linear optical behavior. These properties make them of potential value in inks, microelectronics, and medical imaging (Tran et al., 2013a). Silver nanoparticles have a huge share in nanotechnology based products used in industrial, clinical and hygiene products. Silver nanoparticles leaching from these medical and domestic products will eventually enter terrestrial ecosystems and will interact with the microbes present in the land and water (Khurana et al., 2014). The comprehensive treatments of environments containing infectious pathogens using advanced disinfectant nanomaterials have been proposed for 
prevention of the outbreaks. Among these nanomaterials, silver nanoparticles (AgNPs) with unique properties of high antimicrobial activity have attracted much interest from scientists and technologists to develop nanosilver-based disinfectant products (Tran et al., 2013a). Intended for these explanations, silver ions have been commonly used in medicine and biology for years, but silver modified with nanotechnological methods provides novel possibilities and powers. Silver nanoparticles have a high activity against a wide range of microbial pathogens (Grampositive and Gram-negative bacteria, fungi, viruses, protozoa as well as multidrug resistance microorganisms) and, as opposed to ions, retain a longer a biological usage (Kędziora et al., 2013). An increasingly common application is the use of silver nanoparticles for antimicrobial coatings, many textiles, keyboards, and biomedical devices now contain silver nanoparticles that continuously release a low level of silver ions to provide protection against bacteria. Even running shoes may be impregnated with silver nanoparticles that can kill some bacteria, keep you smelling sweet and preventing the spread of infection. Frontline defenses, such as environmentally benign and cost-effective antibacterial compounds could prevent such infective agents spreading through contact with computer keyboard, phones and other devices (Aggarwal, 2012). The commercially available nanosilver products make broad claims about the power of their nano-Ag ingredients, such as: "eliminates $99 \%$ of bacteria" renders material "permanently antimicrobial and antifungal", "kills approximately 650 kinds of harmful germs and viruses", and "kills bacteria in a short time as 30 minutes ... 25 times faster than other forms of silver" (Bata-Vidács et al., 2013). Carboxymethyl chitosan (CMCTS) and silver nanoparticles (Ag NPs) were successfully linked onto a cotton fabric surface through a simple mist modification process. The CMCTS binder was covalently linked to the cotton fabric via esterification and the AgNPs were tightly adhered to the fiber surface by coordination bonds with the amine groups of CMCTS. As a result, the coating of Ag NPs on the cotton fabric showed excellent antibacterial properties and laundering durability. After 50 consecutive laundering cycles, the bacterial reduction rates (BR) against both $S$. aureus and $E$. coli remained over $95 \%$. It has potential applications in a wide variety of fields such as sportswear, socks, and medical textile (Xu et al., 2017). The silver content has to be high enough to inhibit the growth of bacteria cells (minimal inhibitory concentration, MIC) or kill $99.9 \%$ of them (minimal bactericidal concentration, MBC). Silver nanoparticles have prolonged activity; thanks to this, they are much better for use as a medical factor than silver ions. However, the risk of such a mechanism decreases the sensitivity of the microorganism (Kedziora et al., 2012a). Applications in the field of medicine include the formulations of many potential antimicrobial agents, which are effective against many human pathogens including multidrug-resistant bacteria (Ingle et al., 2008). Resistance of fungal infections has emerged in recent years and is a major health problem (Dar et al., 2013). Silver displays activity against bacteria (grampositive and gram-negative) (Chaloupka et al., 2010; Jasiorski et al., 2009; Kedziora et al., 2012b; Wiglusz et al., 2012); fungi (Gajbhiye et al., 2009); and viruses (Lara et al., 2010). The study also confirmed high efficacy against multidrug resistance bacteria (Guzman et al., 2015). Sterilization in healthcare settings and drinking water are two major applications of disinfectants. Currently chlorine is the most popular disinfectant for water treatment and glutaraldehyde as well as peracetic acid are widely used for sterilization of medical devices and environmental surfaces. To be an ideal disinfectant, an antimicrobial agent should have no residual toxicity and stable in 
applied environments (Barbut et al., 2009). Nevertheless, certain disadvantages such as formation of toxic and sensitizing byproducts associated with chlorine (Sharma et al., 2014) and glutaraldehyde (González Jara et al., 2013) and high instability of peracetic acid (Wang et al., 2015) have made doubts about their usage. Two of those best disinfectants known until now are Hydrogen peroxide $\left(\mathrm{H}_{2} \mathrm{O}_{2}\right)$ and silver that their strong bactericidal activities have been studied on different bacteria (Martin et al., 2015). Strong disinfection effect of $\mathrm{H}_{2} \mathrm{O}_{2}+\mathrm{Ag}^{+}$against three human pathogens including Proteus mirabilis, Klebsiella pneumonia and Escherichia coli has been demonstrated. The efficacy of $30 \mathrm{ppb}$ silver in $0.3 \%$ Hydrogen peroxide solution for disinfection of selected enterobacteria was assessed (Davoudi et al., 2013). Nanosilver can be used in a liquid form, such as a colloid (coating and spray) or contained within a shampoo (liquid) and can also appear embedded in a solid such as a polymer master batch or be suspended in a bar of soap (solid). A wide range of nanosilver applications has emerged in consumer products ranging from disinfecting medical devices and home appliances to water treatments (Tran et al., 2013b). Silver ions have been normally used in medicine and biology for years, but silver particles altered with nanotechnological methods offers new possibilities. Silver nanoparticles account for greater than $23 \%$ of all nanoproducts and have been widely used for diagnostic and therapeutic applications (e.g. in wound healing, arthritic disease, etc.). These have been widely known for their antibacterial, antifungal, and antiviral effects (Midha et al., 2016). Multi resistance to antibiotics is a serious and disseminated clinical problem, common to several new compounds that block the resistance mechanism. The AgNPs could be evaluated as antimicrobial agents for potential use as a barrier control of hospital acquired infections.

\section{MATERIALS AND METHODS}

Sample Locations: Samples were taken from representative different classes and locations in pharmaceutical facility including:

1. Area Class A (the highest grade of cleanliness): Microbiology laboratory laminar air flow units.

2. Area Class $\mathrm{C}$ (intermediate measure of cleanliness): Syrup dosage form preparation area, soft gelatin area.

3. Area Class D (low measure of cleanliness): Solid dosage form preparation areas.

Sample Collection: Air sampler was placed in the center of each room at a height of approximately 1 meter above the floor. One thousand liters of air sampling were obtained by Merck Mass 100 (Figure 1) centrifugal sampler. The Tryptic soya agar plates (TSA) were incubated for 48 hours at $30^{\circ} \mathrm{C}-35^{\circ} \mathrm{C}$ and then for 72 hours at $20^{\circ} \mathrm{C}-25^{\circ} \mathrm{C}$. After incubation, the colonies were counted and recorded in specific protocols.

Swab samples were collected by removing a sterile swab from a sterile tube, moistening it by inserting it into a second tube which contained a sponge soaked with sterile $1.5 \mathrm{ml}$ of phosphate buffered saline (PBS) at $\mathrm{pH}$ 7.2. The selected surface was swabbed by moving the swab back and forth across the surface with several horizontal strokes, then several vertical strokes. The swab was rotated during sampling to ensure that the entire surface of the swab was used. After sampling, the swab was returned to its pre-labeled sampling tube containing appropriate amount of liquid media.

Surface sampling was performed with raised RODAC plates. The tryptone soya agar in contact plates was mixed with polysorbate 80 and lecithin, which inactivate many residual disinfectants. 
Polysorbate 80 neutralizes phenols, hexachlorophene, and formalin, and lecithin inactivates quaternary ammonium compounds. During sampling, a contact plate was pressed onto the area to be tested. Any microorganisms on the surface of the area tested (which should ideally be flat) were transferred onto the contact plate. After the sample had been obtained; the area tested had been wiped down with isopropyl alcohol $70 \%$ to remove any residue left by the contact plate. The contact Plates were placed upside down in the incubator for 48 hours at $30^{\circ} \mathrm{C}-35^{\circ} \mathrm{C}$ and then for 72 hours at $20^{\circ} \mathrm{C}-25^{\circ} \mathrm{C}$.

Antibacterial and antifungal activities: Antibacterial and antifungal activities was performed with synthesized silver nanoparticles by disc diffusion method against a number of reference strains (Escherichia coli ATCC 8739, Salmonella Typhimurium ATCC 6538, Klebsiella pneumonia ATCC 10031, Pseudomonas aerugenosa ATCC 16404, Bacillus spizizenii ATCC 6633, Staphylococcus aureus ATCC 6538, Candida albicans ATCC 10231 and Aspergillus niger ATCC 16404). The freshly prepared cultures were homogenized with melted Mueller-Hinton agar media at about $45^{\circ} \mathrm{C}$. Discs soaked in synthesized AgNPs solution were transferred into the surface of solid inoculated media, plates were incubated overnight at $30-35^{\circ} \mathrm{C}$.

Mixing with other antiseptics: Fungal contaminant was isolated from Capsule filling Machine and confirmed by differential (RBC) culture media and examined against 3 types of disinfectants with different concentrations $\left(\mathrm{Ag}-\mathrm{H}_{2} \mathrm{O}_{2}\right.$ solution, $\mathrm{H}_{2} \mathrm{O}_{2}$ and Ethanol $70 \%$ ) to compare between their effectiveness to inhibit fungal growth. Stock solutions of $\mathrm{Ag}-\mathrm{H}_{2} \mathrm{O}_{2}$ were $50 \%$ hydrogen peroxide (Merck) and 500 ppm silver synthesized before; the treatment solution was freshly prepared in deionized water.

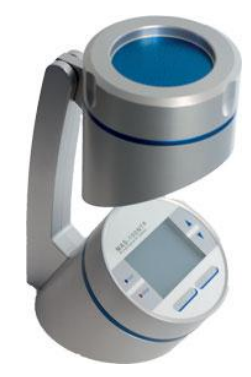

Figure 1 Merck Mass 100 Active Air Sampler

\section{Statistical analysis}

Data were analyzed with Statistical Package for the Social Sciences (SPSS version 20.0) (Statistical Package for the Social Sciences). According to the type of data qualitative represent as number and percentage, quantitative continues group represent by mean $\pm \mathrm{SD}$, the following tests were used to test differences for significance; Differences between frequencies (qualitative variables) and percentages in groups were compared by Chi-square test. Differences between parametric quantitative independent multiple groups by ANOVA non parametric by Krusskle Wallace.ROC curve for cut off, Kappa agreement to test the agreement .non parametric correlation by Spearman's correlation. $\mathrm{P}$ value was set at $\mathrm{t}<0.05$ for significant results $\&<0.001$ for high significant result.

\section{RESULTS AND DESCUSSION}

Results of environmental monitoring samples taken from different locations in pharmaceutical facility:

Surface monitoring: All samples were taken using contact plates from production area and microbiology laboratory in facility except sterility test isolator samples were taken by swab technique. Results were shown in Table (1). All samples of class A showed no growth. All 517 of class $\mathrm{C}$ and $\mathrm{D}$ showed microbial count. 
Table 1 Results of Microbiological monitoring (CFU) of wall surfaces

\begin{tabular}{|c|c|c|c|c|c|c|}
\hline $\begin{array}{c}\text { Year } \\
2017\end{array}$ & $\begin{array}{c}\text { Microbiology } \\
\text { laboratory }\end{array}$ & $\begin{array}{c}\text { Semi-Solid } \\
\text { Area }\end{array}$ & $\begin{array}{c}\text { Dispensing } \\
\text { Room }\end{array}$ & $\begin{array}{c}\text { Soft } \\
\text { Gelatin } \\
\text { Area }\end{array}$ & Solid Area & Syrup Area \\
\hline Qrt.1 & 5 & 10 & 12 & 11 & 15 & 12 \\
\hline Qrt.2 & 9 & 13 & 12 & 10 & 21 & 17 \\
\hline Qrt.3 & 10 & 20 & 17 & 10 & 21 & 11 \\
\hline Qrt.4 & 13 & 14 & 12 & 12 & 47 & 23 \\
\hline Max. & 13 & 20 & 17 & 12 & 47 & 23 \\
\hline
\end{tabular}

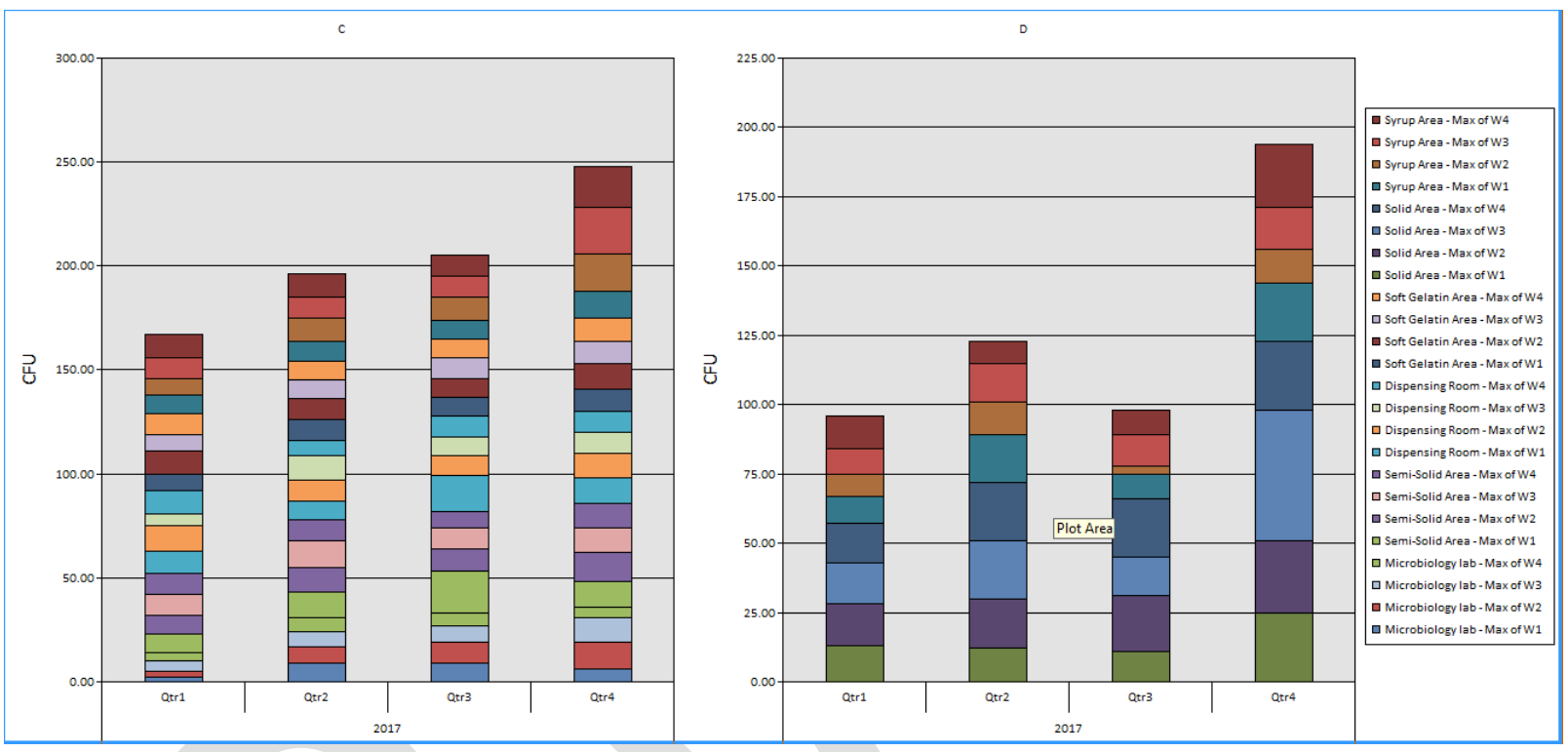

Figure 1. Microbiological monitoring (CFU) of wall surfaces.

Table 2. Results of Microbiological monitoring of Active air

\begin{tabular}{|l|c|c|c|c|c|c|}
\hline $\begin{array}{c}\text { Year } \\
\mathbf{2 0 1 7}\end{array}$ & $\begin{array}{c}\text { Microbiology } \\
\text { lab }\end{array}$ & $\begin{array}{c}\text { Semi- } \\
\text { Solid } \\
\text { Area }\end{array}$ & $\begin{array}{c}\text { Dispensing } \\
\text { Room }\end{array}$ & $\begin{array}{c}\text { Soft } \\
\text { Gelatin } \\
\text { Area }\end{array}$ & Solid Area & Syrup Area \\
\hline Qrt.1 & 10 & 28 & 25 & 25 & 44 & 36 \\
\hline Qrt.2 & 31 & 27 & 35 & 23 & 52 & 33 \\
\hline Qrt.3 & 22 & 29 & 33 & 32 & 61 & 41 \\
\hline Qrt.4 & 30 & 32 & 27 & 28 & 52 & 35 \\
\hline Max. & 30 & 32 & 33 & 32 & 52 & 41 \\
\hline
\end{tabular}




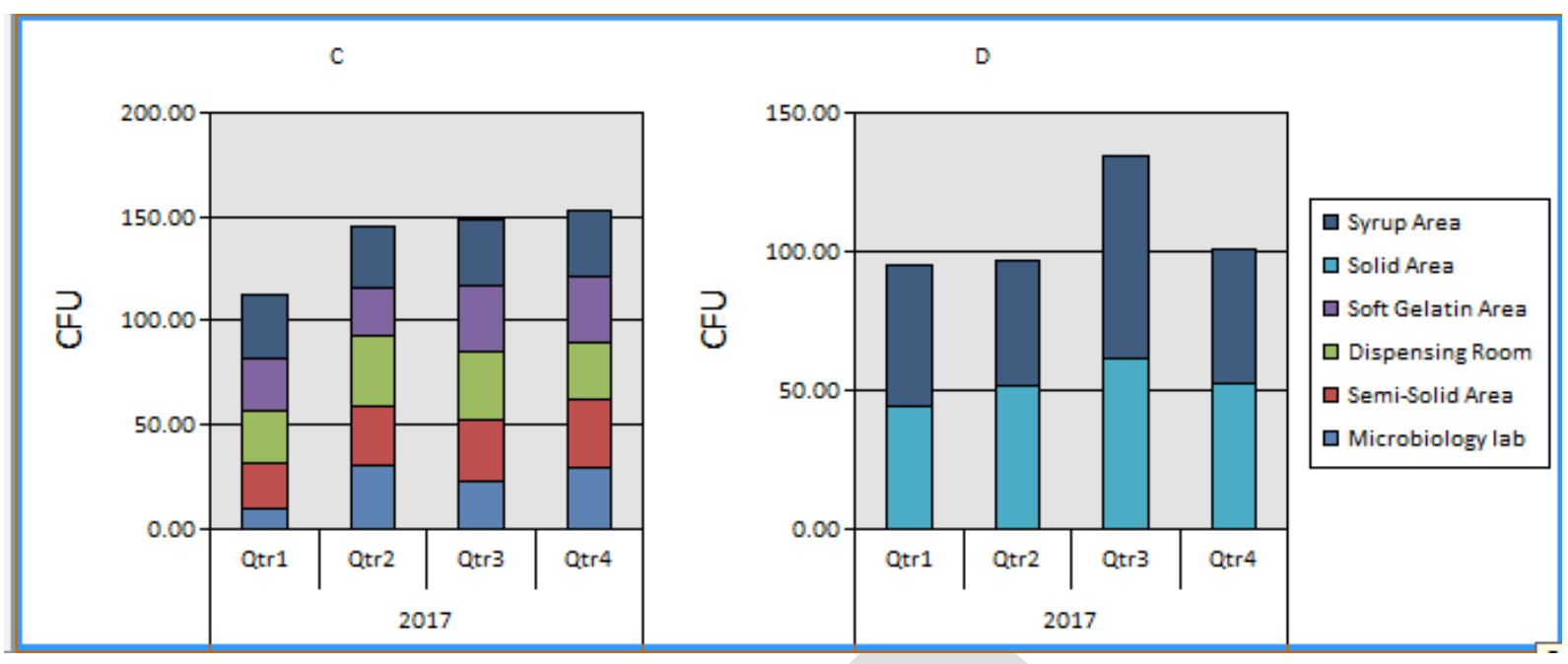

Figure 2. Microbiological Monitoring diagram of active air
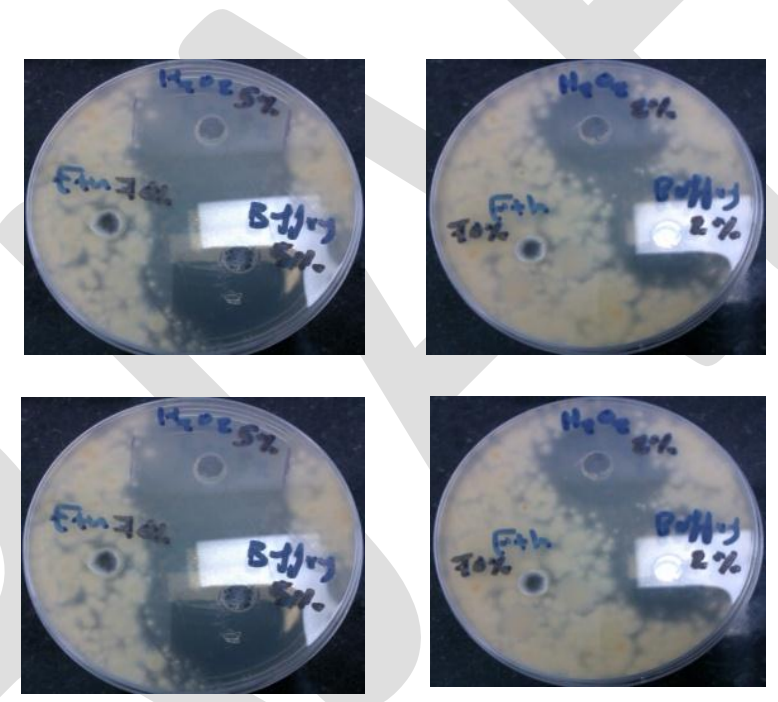

Figure 3. Photocopy of inhibitory effect of using different disinfectants

Table 3. Comparison between Inhibitory affects $\mathrm{H}_{2} \mathrm{O}_{2} \mathrm{Ag}-\mathrm{H}_{2} \mathrm{O}_{2}$ Concentrations

\begin{tabular}{|c|c|c|c|c|}
\hline Disinfectant & $\mathbf{A g - H _ { 2 }} \mathbf{O}_{\mathbf{2}}$ & $\mathbf{A g}-\mathbf{H}_{2} \mathbf{O}_{\mathbf{2}}$ & $\mathbf{H}_{2} \mathbf{O}_{2}$ & $\mathbf{H}_{\mathbf{2}} \mathbf{O}_{\mathbf{2}}$ \\
\hline Concentration & $5 \%$ & $2 \%$ & $5 \%$ & $2 \%$ \\
\hline Zone $(\mathrm{mm})$ & 28.35 & 25.70 & 26.71 & 23.90 \\
\hline
\end{tabular}




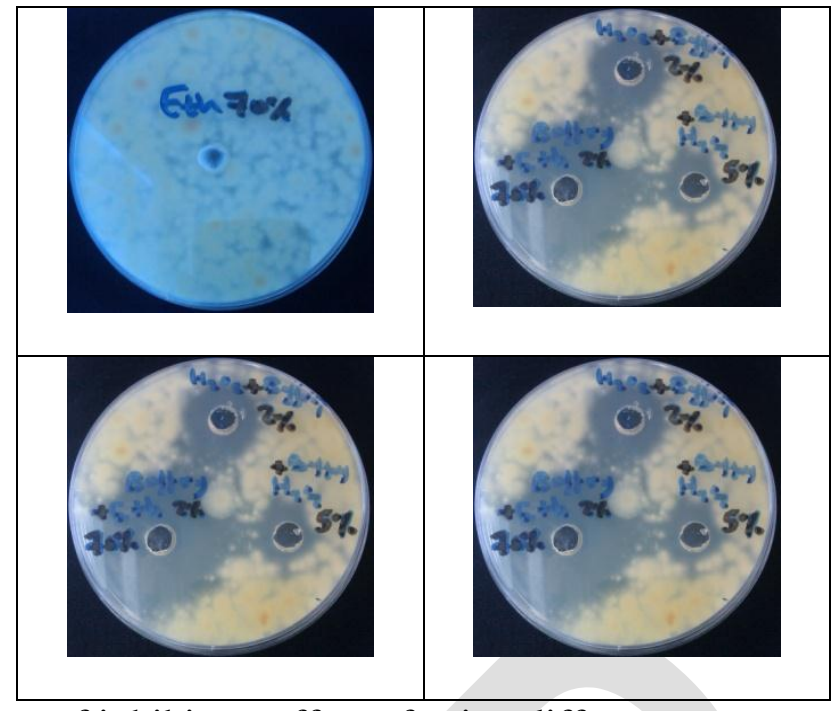

Figure 4. Photocopy of inhibitory effect of using different concentrations disinfectants

Table 4. Comparison between Inhibitory affects Ethanol 70\%, Ag- $\mathrm{H}_{2} \mathrm{O}_{2}$ Concentrations.

\begin{tabular}{|r|c|c|c|c|}
\hline Disinfectant & Ethanol & $\mathbf{A g}-\mathbf{H}_{\mathbf{2}} \mathbf{O}_{\mathbf{2}}$ \& Ethanol & $\mathbf{A g}-\mathbf{H}_{\mathbf{2}} \mathbf{O}_{\mathbf{2}}$ & $\mathbf{A g}-\mathrm{H}_{\mathbf{2}} \mathbf{O}_{\mathbf{2}}$ \\
\hline Concentration & $70 \%$ & $2 \%-70 \%$ & $5 \%$ & $2 \%$ \\
\hline Zone $(\mathrm{mm})$ & 0.0 & 14.62 & 32.97 & 18.92 \\
\hline
\end{tabular}

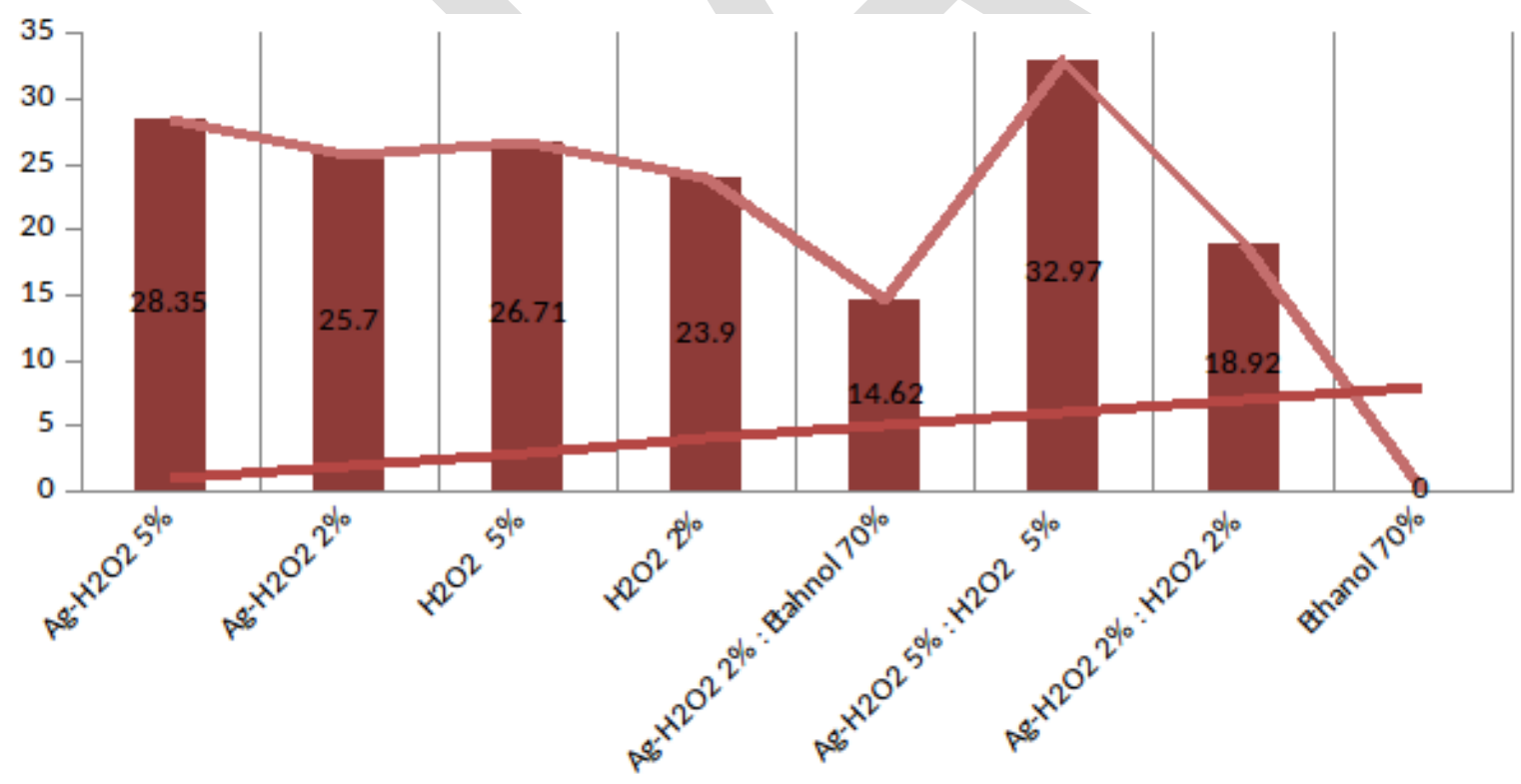

Figure 5. Comparison between Inhibitory affects Ethanol 70\%, Ag- $\mathrm{H} 2 \mathrm{O} 2$ Concentrations.

\section{DISCUSSION}

The more serious problem arising from microbial contamination of pharmaceutical environments. The study findings have shown that all tested samples were microbiologically contaminated. The majority of microbial contaminants in nonsterile pharmaceuticals.

The antibacterial activities of synthesized silver nanoparticles were tested against 
reference microorganisms as shown in (Error! Reference source not found.). The silver nanoparticles exhibited antibacterial activity against both single cell, filamentous fungi, Gram positive and Gram-negative bacteria.

After 3 days of incubation; the results shows the following:

1. Ethanol $70 \%$ has no effect on the microbial growth.

2. $\mathrm{Ag}-\mathrm{H}_{2} \mathrm{O}_{2}$ solution (2\% and $5 \%$ ) Inhibit the microbial growth.

3. $\mathrm{H}_{2} \mathrm{O}_{2}$ solution (2\% and $5 \%$ ) Inhibit the microbial growth.

4. $\mathrm{Ag}-\mathrm{H}_{2} \mathrm{O}_{2}$ solutions $(2 \%, 5 \%)$ more effective than $\mathrm{H}_{2} \mathrm{O}_{2}(2 \%, 5 \%)$ solutions.

5. Mixing between $\mathrm{Ag}-\mathrm{H}_{2} \mathrm{O}_{2}$ solution $2 \%$ with $\mathrm{H}_{2} \mathrm{O}_{2} 2 \%$ solutions or Ethanol $70 \%$ decrease its efficacy (antagonistic effectiveness).

\section{REFERENCES}

Aggarwal, P.J. and V. (2012). Synthesis, Characterization and Antimicrobial Effects of Silver Nanoparticles from Microorganisms-A Review. Int. J. Nano Mater. Sci. 1, 108-120.

Antunes, A., Fierro, I., Guerrante, R., Mendes, F., and Alencar, M.S. de M. (2013). Trends in nanopharmaceutical patents. Int. J. Mol. Sci. 14, 7016-7031.

Ashrafpour, S., Moghadam, T.T., and Ranjbar, B. (2014). Fluorescence Spectroscopy of Lysozyme-Silver Nanoparticles Complex. World Acad. Sci. Eng. Technol. Int. J. Chem. Mol. Nucl. Mater. Metall. Eng. 8, 985-988.

Bata-Vidács, I., Adányi, N., Beczner, J., Farkas, J., and Székács, A. (2013). Nanotechnology and microbial food safety. Microb. Pathog. Strateg. Combat. Them Sci. Technol. Educ. Formatex Zubaran 155-159.
Chaloupka, K., Malam, Y., and Seifalian, A.M. (2010). Nanosilver as a new generation of nanoproduct in biomedical applications. Trends Biotechnol. 28, 580588.

Dar, M.A., Ingle, A., and Rai, M. (2013). Enhanced antimicrobial activity of silver nanoparticles synthesized by Cryphonectria sp. evaluated singly and in combination with antibiotics. Nanomedicine Nanotechnol. Biol. Med. 9, 105-110.

Davoudi, M.., Vakili, T.., Absalan, A.., Ehrampoush, M.H.., and Ghaneian, M.T.. (2013). Antibacterial effects of Hydrogen peroxide and silver composition on selected pathogenic enterobacteria. Middle East J. Sci. Res. 13, 710-715.

Durán, N., Marcato, P.D., De Conti, R., Alves, O.L., Costa, F.T.M., and Brocchi, M. (2010). Potential use of silver nanoparticles on pathogenic bacteria, their toxicity and possible mechanisms of action. J. Braz. Chem. Soc. 21, 949-959.

Etheridge, M.L., Campbell, S.A., Erdman, A.G., Haynes, C.L., Wolf, S.M., and McCullough, J. (2013). The big picture on nanomedicine: the state of investigational and approved nanomedicine products. Nanomedicine Nanotechnol. Biol. Med. 9, $1-14$.

Filipe,

J.A.

(2015).

NANOTECHNOLOGY AND MEDICINE IMPROVEMENT. Int. J. Acad. Res. 7.

Firdhouse, M.J., and Lalitha, P. (2015). Biosynthesis of silver nanoparticles and its applications. J. Nanotechnol. 2015.

Fulekar, M.H., Pathak, B., and Kale, R.K. (2014). Nanotechnology: perspective for environmental sustainability. In Environment and Sustainable Development, (Springer), pp. 87-114. 
Gajbhiye, M., Kesharwani, J., Ingle, A., Gade, A., and Rai, M. (2009). Fungusmediated synthesis of silver nanoparticles and their activity against pathogenic fungi in combination with fluconazole. Nanomedicine Nanotechnol. Biol. Med. 5, 382-386.

Gopinath, S.M., Saha, N.S., V, J.J., Khanum, N.S., Ganesh, S., and M, A.P.G. (2013a). Biological Synthesis, Characterization and Application of Silver Nano Particles - a Review. Int. J. Pharm. Appl. 4, 19-28.

Gopinath, S.M., Saha, N.S., V, J.J., Khanum, N.S., Ganesh, S., and M, A.P.G. (2013b). Biological Synthesis , Characterization and Application of Silver Nano Particles - a Review. Int. J. Pharm. Appl. 4, 19-28.

Gupta, S.R.N. (2014). Advances in Molecular Nanotechnology from Premodern to Modern Era. Int. J. Mater. Sci. Eng. 2, 99-106.

Guzman, M., Dille, J., and Godet, S. (2015). Synthesis and antibacterial activity of silver nanoparticles against grampositive and gram-negative bacteria. Nanomedicine Nanotechnol. Biol. Med. 8, 37-45.

Hajipour, M.J., Fromm, K.M., Akbar Ashkarran, A., Jimenez de Aberasturi, D., Larramendi, I.R. de, Rojo, T., Serpooshan, V., Parak, W.J., and Mahmoudi, M. (2012). Antibacterial properties of nanoparticles. Trends Biotechnol. 30, 499511.

Ingle, A., Gade, A., Pierrat, S., Sonnichsen, C., and Rai, M. (2008). Mycosynthesis of Silver Nanoparticles Using the Fungus Fusarium acuminatum and its Activity Against Some Human Pathogenic Bacteria. Curr. Nanosci. 4, 141-144.
Irena Maliszewska (2011). Microbial Synthesis of Metal Nanoparticles. In Metal Nanoparticles in Microbiology, (Springer), pp. 17-36.

Jasiorski, M., Leszkiewicz, A., Brzeziński, S., Bugla-Płoskońska, G., Malinowska, G., Borak, B., Karbownik, I., Baszczuk, A., Stręk, W., and Doroszkiewicz, W. (2009). Textile with silver silica spheres: its antimicrobial activity against Escherichia coli and Staphylococcus aureus. J. Sol-Gel Sci. Technol. 51, 330-334.

Kalishwaralal, K., Deepak, V., Ramkumarpandian, S., Nellaiah, H., and Sangiliyandi, G. (2008). Extracellular biosynthesis of silver nanoparticles by the culture supernatant of Bacillus licheniformis. Mater. Lett. 62, 4411-4413.

Kedziora, A., Strek, W., Kepinski, L., Bugla-Ploskonska, G., and Doroszkiewicz, W. (2012a). Synthesis and antibacterial activity of novel titanium dioxide doped with silver. J. Sol-Gel Sci. Technol. 62, 79-86.

Kedziora, A., Strek, W., Kepinski, L., Bugla-Ploskonska, G., and Doroszkiewicz, W. (2012b). Synthesis and antibacterial activity of novel titanium dioxide doped with silver. J. Sol-Gel Sci. Technol. 62, 79-86.

Kędziora, a, Gorzela, K., and Bugla-p, G. (2013). Positive and Negative Aspects of Silver Nanoparticles Usage. Biol. Int. 53, 10.

Khurana, C., Vala, A.K., Andhariya, N., Pandey, O.P., and Chudasama, B. (2014). Antibacterial activities of silver nanoparticles and antibiotic-adsorbed silver nanoparticles against biorecycling microbes. Environ. Sci. Process. Impacts 16, 2191-2198.

Kim, B.Y.S., Rutka, J.T., and Chan, W.C.W. (2010). Nanomedicine. N. Engl. J. Med. 363, 2434-2443. 
Lara, H.H., Ayala-Nuñez, N.V., IxtepanTurrent, L., and Rodriguez-Padilla, C. (2010). Mode of antiviral action of silver nanoparticles against HIV-1. J. Nanobiotechnology 8,1 .

Li, W.-R., Xie, X.-B., Shi, Q.-S., Duan, S.S., Ouyang, Y.-S., and Chen, Y.-B. (2011). Antibacterial effect of silver nanoparticles on Staphylococcus aureus. Biometals Int. J. Role Met. Ions Biol. Biochem. Med. 24, 135-141.

Liu, M., Johnston, M.B., and Snaith, H.J. (2013). Efficient planar heterojunction perovskite solar cells by vapour deposition. Nature 501, 395.

Loeve, S. (2015). Of drug administration, war and oïkos: mediating cancer with nanomedicines. Nanomed. 10, 3261-3274.

Luo, D., Carter, K.A., and Lovell, J.F. (2015). Nanomedical engineering: shaping future nanomedicines. Wiley Interdiscip. Rev. Nanomed. Nanobiotechnol. 7, 169188.

Mahapatra, I., Clark, J., Dobson, P.J., Owen, R., and Lead, J.R. (2013). Potential environmental implications of nanoenabled medical applications: critical review. Environ. Sci. Process. Impacts 15, 123-144.

Natarajan, K., Selvaraj, S., and Murty, V.R. (2010). Microbial production of silver nanoparticles. Dig. J Nanomat Biostruct 5, 135-140.

Oldenburg, S.J., and Ph, D. (2014). Silver Nanoparticles : Properties and. 1-7.

Radzig, M.A., Nadtochenko, V.A., Koksharova, O.A., Kiwi, J., Lipasova, V.A., and Khmel, I.A. (2013). Antibacterial effects of silver nanoparticles on gram-negative bacteria: influence on the growth and biofilms formation, mechanisms of action. Colloids Surf. B Biointerfaces 102, 300-306.
Rai, M., Gade, A., and Yadav, A. (2011). Biogenic Nanoparticles: An Introduction to What They Are, How They Are Synthesized and Their Applications. In Metal Nanoparticles in Microbiology, (Springer Berlin Heidelberg), pp. 1-14.

Sau, T.K.; R. (2010). Nonspherical Noble Metal Nanoparticles: Colloid-Chemical Synthesis and Morphology Control.

Tran, Q.H., Nguyen, V.Q., and Le, A.-T. (2013a). Silver nanoparticles: synthesis, properties, toxicology, applications and perspectives. Adv. Nat. Sci. Nanosci. Nanotechnol. 4, 33001.

Tran, Q.H., Nguyen, V.Q., and Le, A.-T. (2013b). Silver nanoparticles: synthesis, properties, toxicology, applications and perspectives. Adv. Nat. Sci. Nanosci. Nanotechnol. 4, 033001.

Wiglusz, R.J., Kedziora, A., Lukowiak, A., Doroszkiewicz, W., and Strek, W. (2012). Hydroxyapatites and europium (III) doped hydroxyapatites as a carrier of silver nanoparticles and their antimicrobial activity. J. Biomed. Nanotechnol. 8, 605612.

Xu, Q., Xie, L., Diao, H., Li, F., Zhang, Y.Y., Fu, F.Y., and Liu, X.D. (2017). Antibacterial cotton fabric with enhanced durability prepared using silver nanoparticles and carboxymethyl chitosan. Carbohydr. Polym. 